\title{
Selective Removal of Barium and Hardness Ions from Brackish Water with Chemically Enhanced Electrodialysis
}

Nahirobe Barragan ${ }^{1 \wedge}$, Deepika Bedi ${ }^{\wedge}$, Mythreyi Sivaraman ${ }^{3}$, Jesus Daniel Loya ${ }^{2}$, Kotono Babaguchi $^{4}$, Michael Findlater ${ }^{2,4}$, Kristin M. Hutchins ${ }^{2}$, Weile Yan ${ }^{1,3 *}$

${ }^{1}$ Department of Civil, Environmental and Construction Engineering, Texas Tech University, Lubbock, Texas 79409, United States

${ }^{2}$ Department of Chemistry and Biochemistry, Texas Tech University, Lubbock, Texas 79409, United States

${ }^{3}$ Department of Civil and Environmental Engineering, University of Massachusetts Lowell, Lowell, Massachusetts 01854, United States

${ }^{4}$ Department of Chemistry and Biochemistry, University of California Merced, Merced, California 95344, United States

$\wedge$ Equal Contribution

* Corresponding Author. Current Affiliation: University of Massachusetts Lowell Tel: (978) 934-2256; Email address: weile_yan@uml.edu 


\section{Experimental Methods}

\section{Aqueous Extraction Experiments}

Aqueous solutions containing $1 \mathrm{mM}$ barium, magnesium, calcium, and various concentrations of sodium nitrate salts were prepared. The initial $\mathrm{pH}$ was adjusted by drop-wise addition of $2 \%$ $\mathrm{HNO}_{3}$ or $0.1 \mathrm{M} \mathrm{NaOH}$ followed by thorough mixing to avoid precipitates formation. Ion

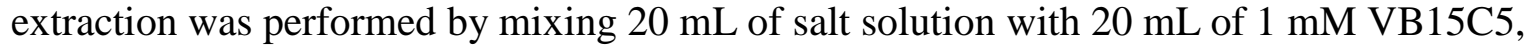
VB18C6, or VB21C7 in DCM in a glass separatory funnel. The funnel was capped with a stopper and was subject to 6 min of intense manual shaking. The mixture was then allowed to sit for 30 min. $1 \mathrm{~mL}$ of the aqueous phase was sampled and was diluted with $2 \% \mathrm{HNO}_{3}$ prior to analysis using ICP-MS. Extraction experiments were performed in duplicates.

\section{Synthesis of Calixarenes}

A stirred benzene $(40 \mathrm{~mL})$ solution of $p$-tert-butylcalix[4]arene $(0.50 \mathrm{~g}, 0.68 \mathrm{mmol})$ and $\mathrm{Cs}_{2} \mathrm{CO}_{3}$ $(0.22 \mathrm{~g}, 0.68 \mathrm{mmol})$ was heated at reflux temperature. To this solution was added pentaethylene glycol ditosylate $(0.37 \mathrm{~g}, 0.68 \mathrm{mmol})$ as a benzene solution $(30 \mathrm{~mL})$ over a period of $1.5 \mathrm{~h}$ in a dropwise fashion. After a further $24 \mathrm{~h}$ of heating at reflux, a second portion of $\mathrm{Cs}_{2} \mathrm{CO}_{3}(0.22 \mathrm{~g}$, $0.68 \mathrm{mmol}$ ) was added, and the reaction mixture allowed to stir at reflux for an additional $24 \mathrm{~h}$. After cooling to room temperature, the mixture was treated with $1 \mathrm{~N} \mathrm{HCl}$ and extracted three times with diethyl ether. The combined organic layers were washed with water and the organic layer separated and concentrated under reduced pressure to afford $p$-tert-butylcalix[4]arenecrown-6 (13) in $30 \%$ yield. Compound $\mathbf{1 3}$ was used without further purification. To a solution of $13(50 \mathrm{mg}, 0.12 \mathrm{mmol})$ in THF-DMF (9:1 v/v) (30 mL) was added sodium hydride ( $15 \mathrm{mg}, 0.6 \mathrm{mmol})$, and the mixture was heated under reflux for $0.5 \mathrm{~h}$. Subsequently ethyl bromoacetate $(80 \mathrm{mg}, 0.48 \mathrm{mmol})$ was added. The reaction mixture was heated under 
reflux for $5 \mathrm{~h}$, and after cooling, the mixture was cautiously poured into ice-cold $\mathrm{HCl}(6 \mathrm{M}, 10$ $\mathrm{mL}$ ). The solvent was evaporated under reduced pressure, and the residue was partitioned between $50 \mathrm{~mL}$ of chloroform and $50 \mathrm{~mL}$ of $0.5 \mathrm{~N} \mathrm{HCl}$. The organic layer was separated and washed with water. The organic solvent was removed under reduced pressure. The crude reaction product was initially obtained via trituration with $80 \%$ ethanol $(10 \mathrm{~mL})$ to give the desired diester (36 mg, 70\%). The crude diester was dissolved in THF (10 mL), tetramethylammonium hydroxide $\left(\mathrm{Me}_{4} \mathrm{NOH}\right)(25 \%$ solution in methanol, $108 \mu \mathrm{L}, 0.25 \mathrm{mmol})$, and water $(5 \mathrm{~mL})$ were added, and the mixture was heated under reflux for $24 \mathrm{~h}$. The cooled mixture was concentrated to dryness and treated with $10 \%$ hydrochloric acid ( $5 \mathrm{~mL})$ to form a precipitate which was filtered off and redissolved in chloroform. The organic layer was washed with water, separated and dried $\left(\mathrm{MgSO}_{4}\right)$ followed by isolation via filtration and subsequent solvent evaporation. The desired product, $p$-tert-butylcalix-[4]arene-crown-6-dicarboxylic acid (14) was obtained as a colorless solid. ${ }^{1} \mathrm{H}$ NMR $\left(\mathrm{CDCl}_{3}, 400 \mathrm{MHz}\right): \delta 7.12(\mathrm{~s}, 4 \mathrm{H}, \mathrm{ArH}), 6.52(\mathrm{~s}$, 4H, ArH), 4.95 (s, 4H, $\left.\mathrm{OCH}_{2}\right), 3.10-4.50$ (m, $28 \mathrm{H}, \mathrm{OCH}_{2} \mathrm{CH}_{2} \mathrm{O}$ and $\left.\mathrm{ArCH}_{2} \mathrm{Ar}\right), 1.32$ (s, 18H, $\left(\mathrm{C}\left(\mathrm{CH}_{3}\right)_{3}\right), 0.81\left(\mathrm{~s}, 18 \mathrm{H}, \mathrm{C}\left(\mathrm{CH}_{3}\right)_{3}\right)$.

\section{Membrane Potential Measurements}

Membrane potential measurements were performed in a two-compartment glass cell (MFC100, Adam \& Chittenden Scientific) with each cell holding liquid upto 150ml. The two compartments were separated by a piece of membrane (effective surface area approximately $27 \mathrm{~cm}^{2}$ ). The flanges of the cell and the membrane were fastened together by a set of clamps. Two $\mathrm{Ag} / \mathrm{AgCl}$ single junction reference electrodes (Bioanalytical Systems) were inserted into the solution, one on each side of the membrane. The electrodes were positioned such that they pointed to the center of the membrane and was approximately $6 \mathrm{~mm}$ away from the membrane surface. The 
compartments were filled with 0.1 and $0.01 \mathrm{M}$ of $\mathrm{Ba}\left(\mathrm{NO}_{3}\right)_{2}$ solution, respectively. The concentration of salt in the solution was maintained constant by connecting each side with a reservoir containing the same solution through a continuous flow loop using peristatic pumps. The solution in each compartment was stirred vigorously using a magnetic stirring bar. Prior to a potential measurement, the membrane was equilibrated with $0.01 \mathrm{M} \mathrm{Ba}\left(\mathrm{NO}_{3}\right)_{2}$ overnight. Once a membrane was installed in the cell, the potential difference across the membrane was monitored by a digital multimeter. Typically, it took approximately $30 \mathrm{~min}$ for the potential reading to stabilize and the reading thereafter (i.e., between 30 to $60 \mathrm{~min}$ ) was recorded and averaged. The potential reading was subtracted by the offset potential, the latter collected using the same set-up except that the concentration of salt on each side was $0.1 \mathrm{M}$. 
Table S1. Potential across the original and modified membrane.

\begin{tabular}{|l|l|}
\hline Membrane & Potential, $\mathrm{mV}$ \\
\hline Unmodified CEM & $18.7 \pm 0.1$ \\
\hline CEM with VB18c6 & $18.2 \pm 0.7$ \\
\hline CEM with calix[4]arene & $17.7 \pm 0.2$ \\
\hline CEM with calix[4]arene-DA & $17.4 \pm 0.1$ \\
\hline
\end{tabular}


Table S2. Final pH readings of diluate and concentrate chamber.

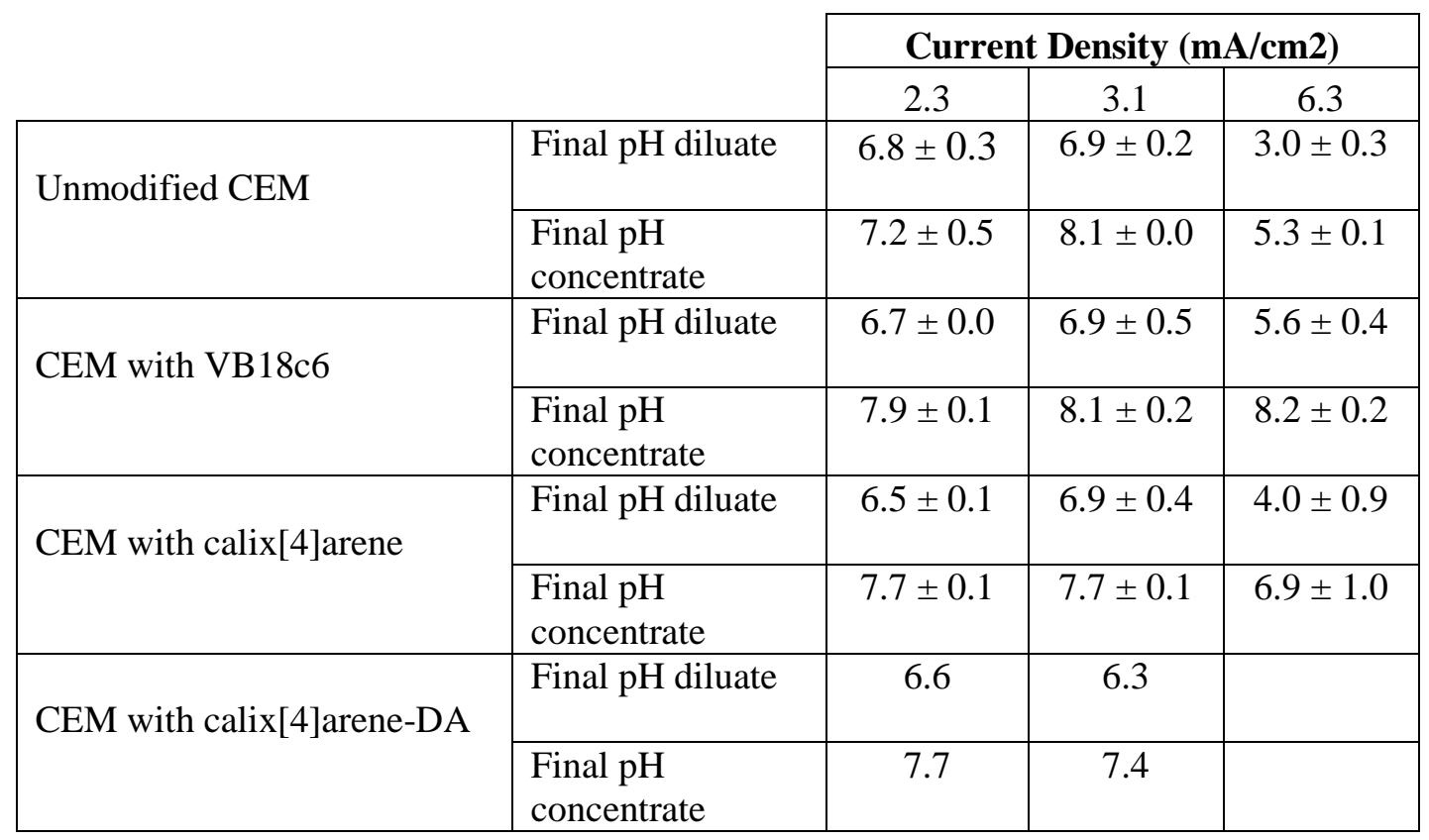



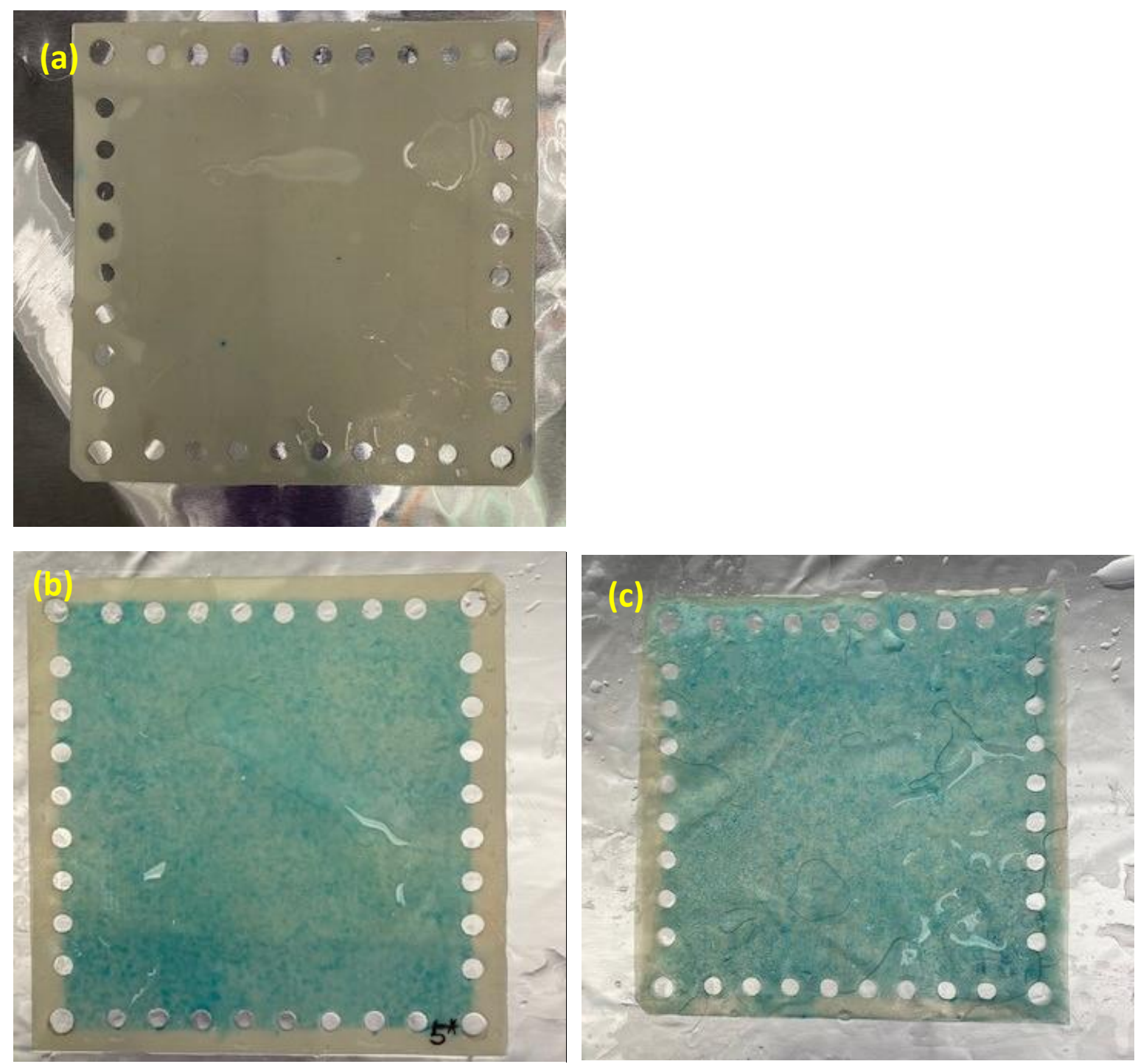

Figure S1. Photos of (a) a pristine membrane and membranes deposited with (b) VB18C6 and (c) calix[4]arene, respectively. The blue coloration of the modified membranes was from methylene blue in the macrocycle solution. 

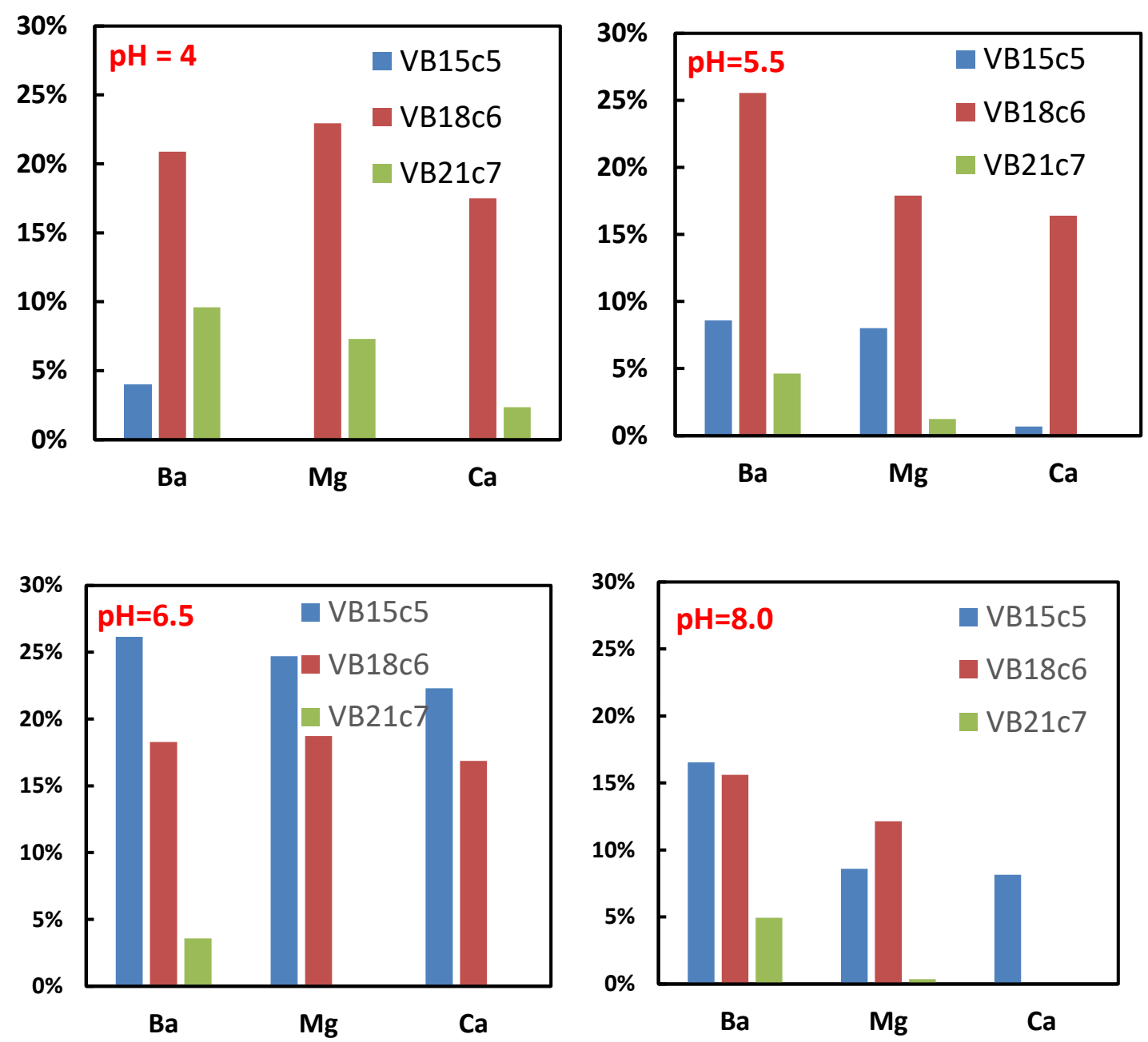

Figure S2. Effect of pH on ion extraction efficincy by crown ethers of different vacity sizes. Concentrations of ions and crown ethers in the extraction experiments were $1 \mathrm{mM}$ each. 

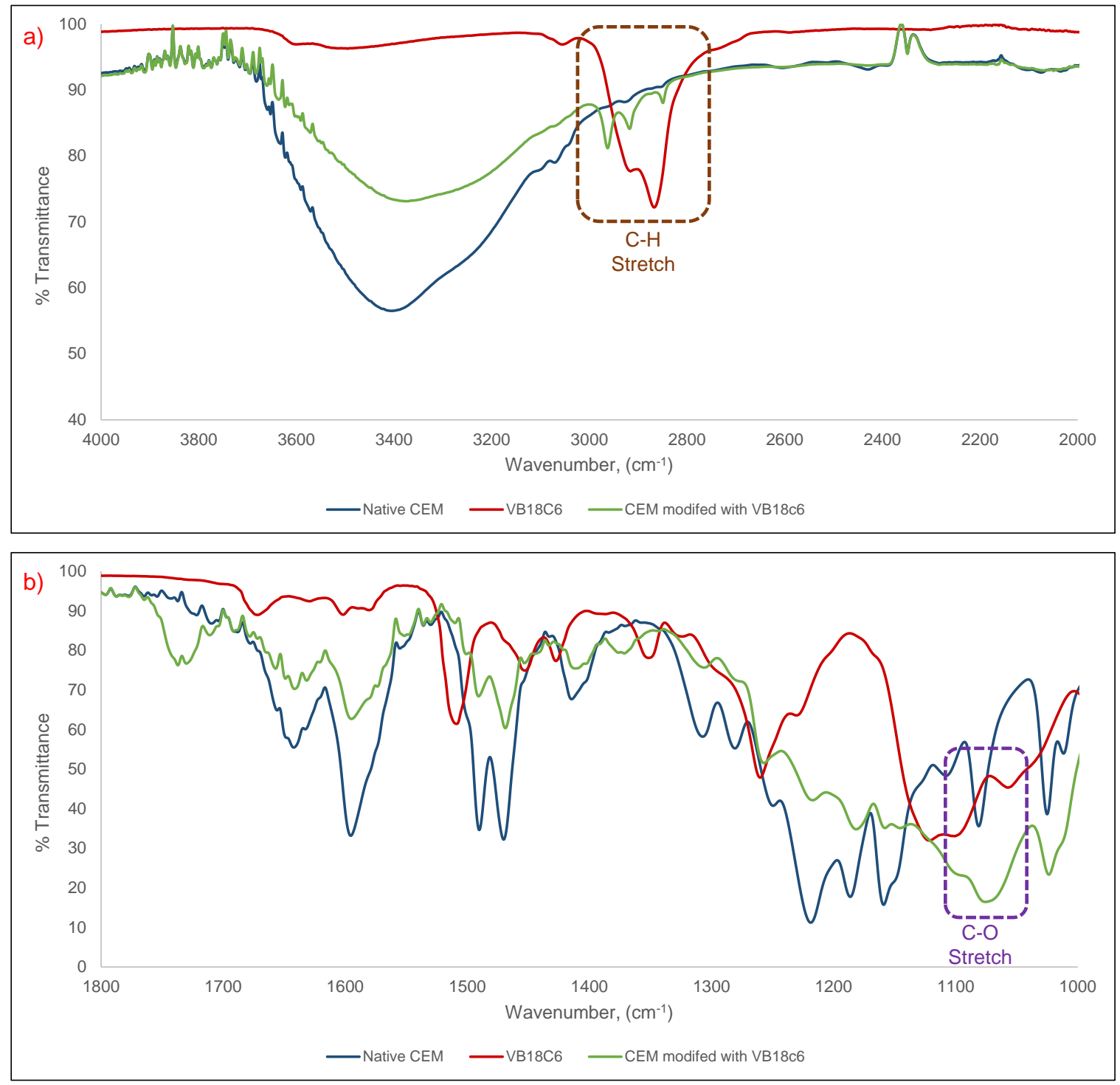

Figure S3. FTIR spectra of original CEM and that coated with VB186C highlighting region from 2000$4000 \mathrm{~cm}^{-1}$ (a) and 1000-1800 $\mathrm{cm}^{-1}$ (b), respectively. 

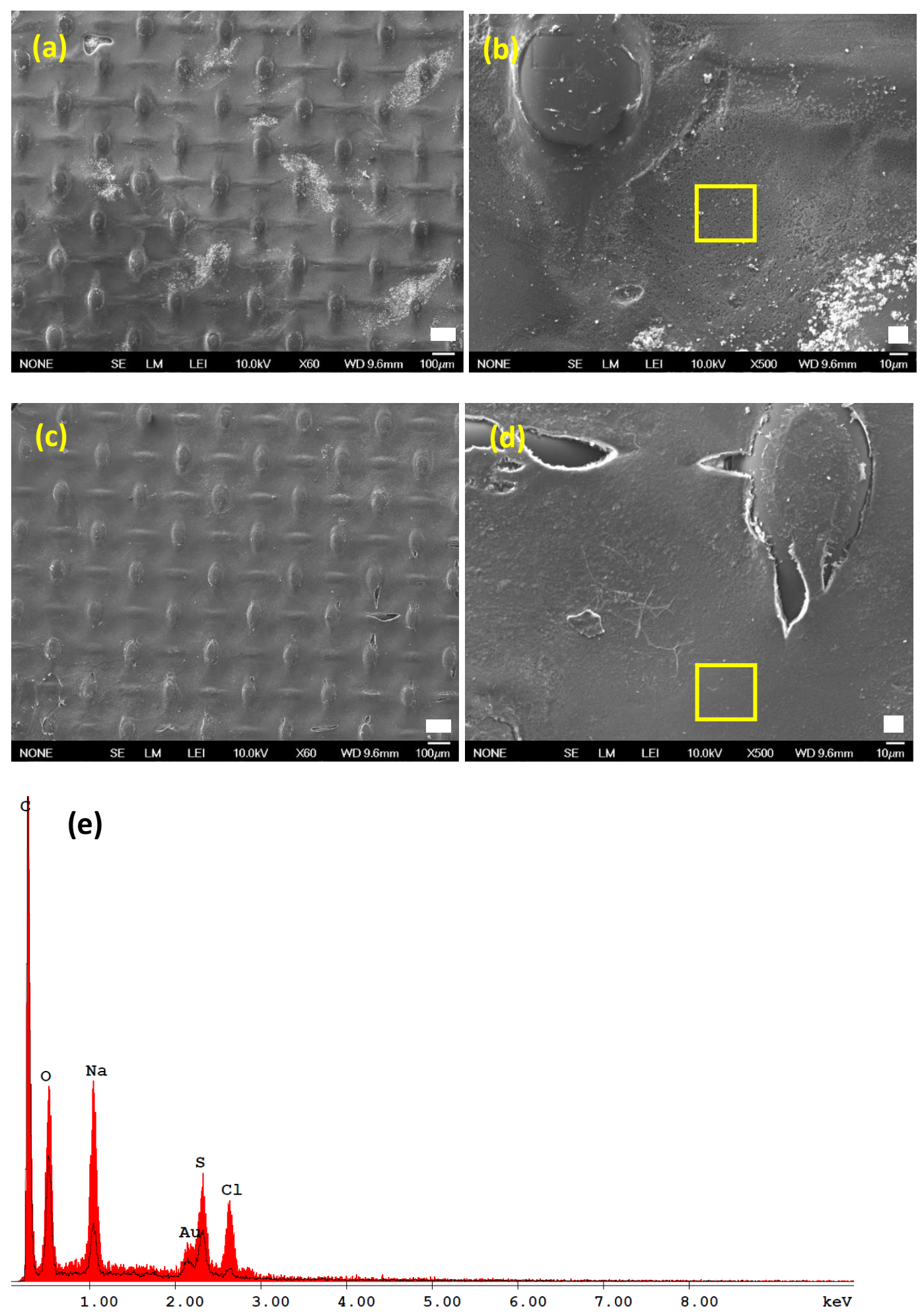

Figure S4. SEM images of unmodified PCSK (a, b) and PCSK deposited with VB18c6 (c, d). Scale bars correspond to 100 and $10 \mu \mathrm{m}$, respectively in low and high-magnification images. White powdery deposits on unmodified PCSK are $\mathrm{NaCl}$ crystallites as confirmed by EDX analysis. (e) Overlay of EDX spectra of the unmodified PCSK (red trace, analysis area indicated 
in (b)) and that modified by VB18C6 (black trace, analysis area indicated in (d)). The spectra were normalized to the $\mathrm{C} \mathrm{X}$-ray line. The lower relative intensities of $\mathrm{Na}, \mathrm{S}$, and $\mathrm{Cl}$ signals of the modified membrane suggest the presence of an attenuating carbon-rich coating on the membrane surface. 

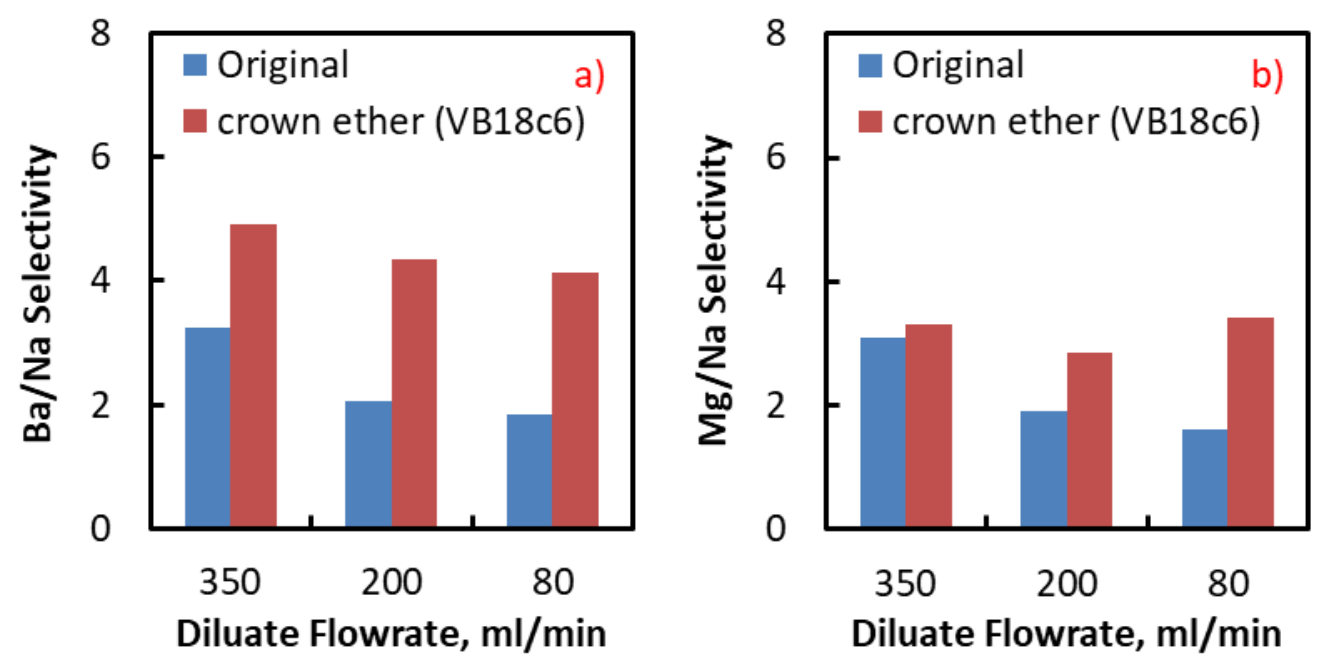

Figure S5. Effect of diluate flow rate on the selectivity of (a) Ba over $\mathrm{Na}$ and (b) $\mathrm{Mg}$ over $\mathrm{Na}$ during electrodialysis. Electrolytes in the feed water were $100 \mathrm{mM} \mathrm{Na}, 5 \mathrm{mM} \mathrm{Mg}$, and $1 \mathrm{mM} \mathrm{Ba}$, respectively. Current density was $3.1 \mathrm{~mA} / \mathrm{cm}^{2}$. 

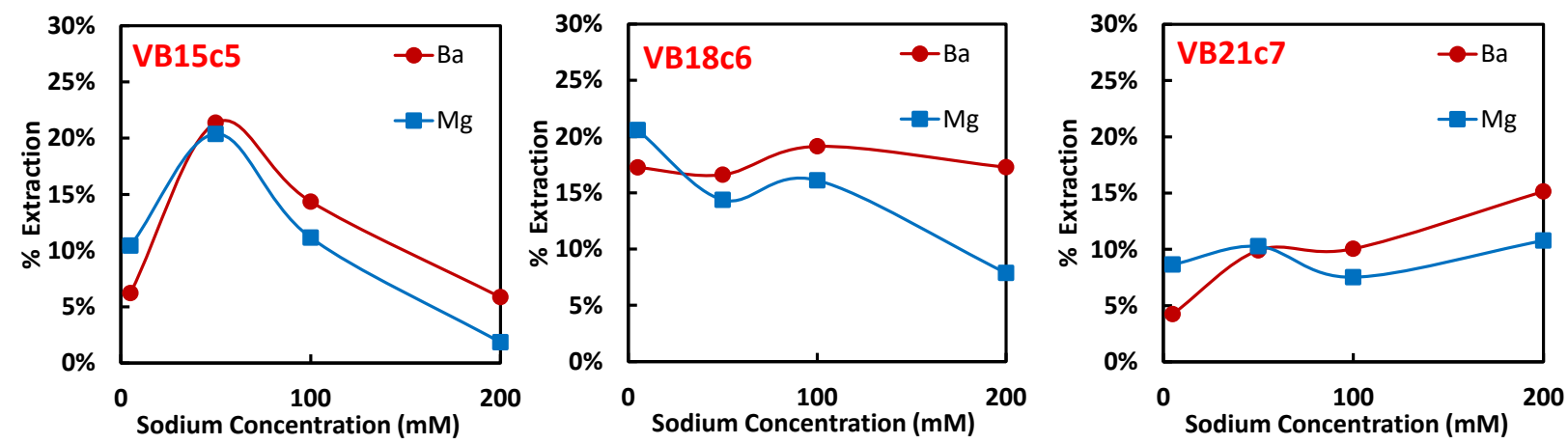

Figure S6. Effect of sodium concentration on ion extraction efficiency by crown ethers of different cavity sizes. Concentrations of $\mathrm{Ba}$ and $\mathrm{Mg}$ ions were $1 \mathrm{mM}$ each. $\mathrm{pH}$ of the extraction solution was 6.5 . 